\title{
Exploring challenges of boundary-crossing performance dialogues in hybrids
}

\author{
Tomi Rajala $^{1}$ (D) Harri Laihonen ${ }^{1} \cdot$ Jarmo Vakkuri $^{1}$
}

Published online: 27 August 2019

(c) The Author(s) 2019

\begin{abstract}
Literature on performance management in hybrid organisations remains lacking, even though they increasingly are providing public services. This study created new knowledge on performance management in hybrid organisations by answering a question that addressed what kinds of challenges are in hybrid organisation's boundary-crossing performance dialogues. Boundary-crossing performance dialogues here refer to performance management discussions between representatives of public and private sector organisations forming the hybrid. To answer the proposed question, a case study approach based on interviews and documents was chosen. Using inductive content analysis, the study identified several challenges that occurred during the boundary-crossing dialogues. This contributes to existing research on performance management in hybrid organisations. For practitioners, the results provide insights for tackling the specific problems of performance management in hybrid organisations.
\end{abstract}

Keywords Hybrid organisation · Performance dialogue - Performance management . Performance governance $\cdot$ Performance information

\section{Introduction}

Hybrid organisations increasingly are providing public services (e.g., McGuire 2002; Christensen and Laegreid 2011). A typical hybrid organisation comprises public and private actors who, through collaboration and cooperation, provide public services for citizens (Johanson and Vakkuri 2017). Extant literature claims

Tomi Rajala

tomi.rajala@tuni.fi

Harri Laihonen

harri.laihonen@tuni.fi

Jarmo Vakkuri

jarmo.vakkuri@tuni.fi

1 Faculty of Management and Business, Tampere University, 33014 Tampere, Finland 
that traditional entity-based performance management systems are inadequate in hybrid organisations and, therefore, performance management systems based on inter-organisational collaboration are being adopted by these types of organisations (Agostino and Arnaboldi 2018). Here, performance management means a 'continuous process of identifying, measuring and developing the performance of individuals and teams and aligning performance with the strategic goals' (Aguinis 2009, p. viii). Adopting inter-organisational performance management systems aims to turn performance management into performance governance that operates within and across public, private and third sector interfaces and relies on inter-sectoral co-processes (Bouckaert and Halligan 2008). One way to create inter-organisational collaboration in performance management is to use dialogue that engages all necessary actors in developing an organisation's performance (Agostino and Arnaboldi 2015). In this article, dialogue that addresses performance management tasks is called performance dialogue.

More specifically, performance dialogue is a phenomenon in which 'participants jointly interpret performance information and discuss it while identifying the actions needed to manage the performance according to this information' (Rajala et al. 2018). Performance dialogue utilises the methods of dialogue and concentrates on performance information (e.g., Moynihan 2005). Performance information includes data about resources, workload, outputs, processes, outcomes and efficiency (Hatry 2006), and it systematically is collected, produced and shared (Van Dooren et al. 2015). Boundary-crossing performance dialogues here refer to performance management discussions between representatives of public and private sector organisations operating in the hybrid; this definition of boundary-crossing dialogues was borrowed from the work of Rajala and Laihonen (2019).

Generally, embedding dialogue in performance management can be beneficial in many ways, as it enables learning and development of organisational practices (Laihonen and Mäntylä 2017). However, performance dialogue simultaneously imposes many challenges on organisations, such as a lack of dialogue skills and motivation to conduct dialogues (Rajala et al. 2018). In this research, we were interested in the specific difficulties of hybridity associated with boundary-crossing performance dialogues that occur between representatives of different organisations forming the hybrid organisation. Therefore, we asked the following question: What kinds of challenges are in hybrid organisation's boundary-crossing performance dialogues? This research question remains unanswered until now. Although Rajala et al. (2018) have studied performance dialogue problems in both hybrid and public organisations, they did not identify challenges of hybridity in boundary-crossing performance dialogues within hybrid organisations. To answer our question, we utilised a case study approach and content analysis. By identifying several challenges that occurred in hybrid organisations' boundary-crossing performance dialogues, we contribute to conversations addressing performance dialogue and performance management practices in hybrid organisations (e.g., Hodges 2012; Rajala et al. 2018). Our results also offer reasons why it is difficult to attain the type of performance governance that is achieved through collaboration between public, private and third sector actors, according to Halligan et al. (2012). We also argue that our results 
provide useful insights into conversations about why performance management does not reach its full potential in hybrid organisations.

The rest of this study is organised as follows. In the next section, we provide more precise conceptual definition of hybrid and we define performance management in hybrids. In the third section, research methods and context are explained. In the fourth section, we present an analytical framework for the content analysis, while the fifth section shows how this original framework was iterated and developed during the empirical analysis. The fifth section also provides the empirical analysis. In the final section, conclusions are presented.

\section{What are hybrid organisations?}

Previous research has demonstrated that hybridity is not an easy concept to define (Johanson and Vakkuri 2017). Theoretically, hybrids have been considered an entity that one cannot explicitly explain (Ménard 2004). Almost everything can become hybrid, as its conceptualisations are associated with exploring 'impure' forms of social organising (Philoppopoulos-Mihalopoulos 2012). Thus, hybrid forms of organising have been defined in various ways.

Extant literature attaches many characteristics to hybrid organisations. First, hybrid organisations can produce public and private goods (Johanson and Vakkuri 2017). Second, mixed ownership in hybrid organisations is common (Hansmann 1996). Mixed ownership indicates that a hybrid organisation has both public and private sector owners (Thynne 2011). Third, different institutional logics, goal congruency and incongruence typically exist in these types of organisations (Johanson and Vakkuri 2017; Kreps and Benoît 2011; Reay and Hinings 2009; Pache and Santos 2013; Eprahim et al. 2014). Fourth, hybrid organisations obtain funding from a variety of sources (Hodge and Greve 2007). Fifth, differentiated forms of economic and social control are exercised in hybrid organisations (Power 1997; Kelly 2005; Jordana and Levi-Faur 2004). For purposes of this research, an organisation formed by different types of legal organisations is called a hybrid organisation, i.e., it comprises public and private or third sector (i.e. voluntary sector) organisations, and these organisations have a common goal that they aim to achieve via collaboration.

\section{Performance management in hybrid and non-hybrid organisations}

The concept of performance management forms from two major aspects: performance measurement and performance information usage that aims to enhance management and other organisational activities (e.g., Aguinis 2009, p. viii.). In public, private and third sector organisations, performance measures viewed in different performance management models can be divided into the same measurement categories: input, process, workload, output, outcome, productivity and cost-effectiveness measures (e.g., Pollitt and Bouckaert 2004; Micheli and Kennerley 2005; Thomas et al. 2008; Schläfke et al. 2012; Van Dooren et al. 2015). Performance measures that are used to report a hybrid organisation's value to the surrounding community also belong to these seven 
performance measurement categories (Liu et al. 2014; Vo et al. 2016). The differences between performance measures used in public, private, third sector and hybrid organisations boil down to the question of what types of measures are used, e.g., output and outcome measures. For example, arrested criminals can be an output measure in the public sector, whereas manufactured cars can be an output measure at a car production plant, part of the private sector.

When considering performance evaluations, public, private, third sector and hybrid organisations are trying to evaluate performance aspects that also can be grouped under the seven aforementioned measurement categories (e.g., Lee and Nowell 2015). Here, the only difference is that performance evaluations are nonroutine events that are designed in a case-by-case manner, whereas performance measurement is a routine event that occurs more or less the same way at different time points because the objective is to produce comparable information (McDavid and Hawthorn 2006).

The complexity of performance measurement and evaluation differs between the hybrid and non-hybrid organisation types. Performance measurement has been viewed as more complex in the public and third sectors than in the private sector (van Helden and Reichard 2016). The fact that no market-price information on several public sector activities exists makes it difficult to evaluate government interventions and public services' impact and attribution (Johanson and Vakkuri 2017). It also has been argued that hybrids, as organisational networks, are more complex to measure than public and third sector organisations, although problems in evaluating and measuring network performance bear a resemblance to complications viewed in the evaluations of public and third sector organisations (Provan and Milward 2001). The private sector networks are also more complex in terms of performance measurement and evaluation compared to a private sector organisation (Kamminga and Van der Meer-Kooistra 2007). At the organisational level, the constituents of public, private and third sector organisations have conflicting views on what is valuable to the organisation and its actions (Cyert and March 1963; Agranoff and McGuire 2001). Assessing networks, such as hybrid organisations, involves more constituents, and this complicates the evaluation, as more conflicting views on the network's value can exist (Johanson and Vakkuri 2017).

Besides the number of constituents, measuring network performance involves more analysis levels because network performance must be considered, and one cannot focus merely on the organisational and community levels, as is the case with private, public and third sector organisations (Provan and Milward 2001). Using performance information for performance management purposes is more complicated as well because developing the performance of individuals and teams and aligning performance with strategic goals involve more actors.

\section{Research setting}

This study applies an explorative case study approach (e.g., Yin 2009). We chose this approach because we wanted to focus on one organisation, as this enabled us to use an in-depth exploration and multiple perspectives in describing the 
chosen hybrid organisation's complexity and uniqueness (e.g., Simons 2009). Using more cases would have limited our opportunity to understand the richness related to the challenges of boundary-crossing performance dialogue in hybrid organisations. Thus, the case selection served the theory-building objective that we aimed to reach (e.g., Thomas 2011). Indeed, the chosen case enabled us to develop the current theory addressing performance dialogue challenges. Overall, our research can be considered an instrumental case study because it provides a general understanding of the challenges present in boundary-crossing dialogues addressing a hybrid organisation's performance. Thus, we aim to understand how things might be in general, not just how things are in the particular organisation that we examined.

The examined hybrid organisation could be defined as the most extreme, as the scope of services provided was diverse and these services were consumed by heterogeneous clientele. In this research, we focussed on the performance dialogues occurring in the steering and coordination groups, which were the hybrid organisation's two main administrative organs. The steering group prepared budget proposals, solved conflicts, monitored goal achievement and carried into practice the hybrid organisation's procedures. The coordination group made operational decisions and prepared matters for the steering group and service market manager. These administrative organs involved representatives from all nine service units operating in the hybrid organisation. These service units were as follows:

1. A government agency that provides basic social security for residents of Finland.

2. A federation of municipalities that produces healthcare services.

3. A private company that generates healthcare services.

4. A third sector organisation, along with municipal and voluntary workers, that arranges art events.

5. A library (a municipal service unit that offers versatile collections and helps information seekers).

6. A maternity and child health clinic (a municipal service unit that supplies social and health services).

7. A youth service (a municipal service unit that provides low-threshold guidance to youths and young adults ages 16-29).

8. A mental health and substance abuse service clinic (a municipal service unit that helps people over age 18 with mental health and substance abuse problems).

9. A citizen service (a municipal service unit serving citizens by distributing information, selling tickets, etc.).

The hybrid organisation's main goal was to make it easier for citizens to use public sector services, which was the biggest reason why it was formed. The second objective was to create an innovation platform that would improve public service production. The hybrid organisation aimed to fulfil its goals by combining the ideas of accessibility and customer orientation into a new technology and public space design that supported public service production and use. The hybrid organisation attempted to provide better services to citizens by generating 
collaborations among different service units. Indeed, active searching for synergies among different units and new ways to collaborate was built into the hybrid's modus operandi. For example, many health-related services were part of the hybrid, and they collaborated to create effective service paths for citizens. Creating effective service paths included joint decisions on different service units' tasks in each service path. Other examples of partnerships included collaborations between the library and youth services, joint briefing sessions and other health education events that the library and health service units arranged for citizens. The steering and coordination groups' activities served the hybrid's objectives, and within these groups, the boundary-crossing performance dialogues that we focussed on in this research occurred.

It was typical for the hybrid's personnel to view citizens' needs in a holistic manner, with service paths between different service units generated accordingly. Thus, personnel in the hybrid saw the citizen not only as their own customer, but also as other service units' customer in the hybrid. From citizens' perspective, it was convenient that the often-used services were provided in same building, lowering the threshold to use public services, according to reports (Kenno 2017).

Our data collection method mainly entailed expert interviews (e.g., Meuser and Nagel 2009), which provided more room for a more in-depth explorative approach, as follow-up questions can be asked and clarifying statements may be requested. Interviews were carried out between November 2016 and March 2017. The semistructured interviews' objective was to determine managers' perceptions of current challenges in boundary-crossing performance dialogues. The shortest interview lasted about $32 \mathrm{~min}$, while the longest one took $70 \mathrm{~min}$. Generally, most interviews lasted about an hour, but all interviews were conducted face to face, audiotaped and transcribed verbatim. Each of the 11 managers was interviewed only once. Only one researcher was sent to conduct each interview. The interviewees were selected through purposive sampling (Patton 2002) and in collaboration with city representatives so that we could locate public managers who participated in the dialogues in which we were interested.

In the hybrid organisation, we interviewed three members from the steering group: the administration and development director, a representative from the library and a representative from a government agency. Then we interviewed five members of the coordination group (the service market manager and representatives from the maternity and child health clinic, library and mental health and substance abuse service clinic). Finally, we interviewed three people from the city's central administration: the director of human resources, the services development director and the project manager. Anonymity for the interviewees was guaranteed and secured; thus, special attention has been paid to preserving anonymity during the sampling and reporting phase. Other researchers listened to the interviews, and feedback was provided to the interviewer if necessary. No biases arising from the interviewer were noticed in the process, and any feedback related mostly to follow-up questions. To triangulate and cross-check the interviews' findings, five documents from the hybrid organisation were analysed (see Table 1).

As an analysis method, inductive content analysis was used. At first, the theoretical framework developed by Rajala et al. (2018) was adopted and used in the 
empirical analysis. However, during the analysis process that took place after all interviews were conducted, we iterated and corrected this framework after going through 50 of the interview transcripts. This method is known as inductive category development, in which new theoretical categories are created from collected empirical data (Mayring 2000). By utilising inductive category development, it was possible to provide more space for interactions between the researchers and research subjects. This space was very useful because our research topic had been unexplored in previous literature, and we did not know exactly what we were looking for when we entered the case organisation. Conducting the study via inductive content analysis gave us the chance to iterate the research setting. Overall, the whole research process can be summarised in 11 steps:

1. Review literature on performance management and identify research gap.

2. From the literature, adopt theoretical categories for the content analysis.

3. Create questions for interviews based on these categories and select semi-structured interviews as the interview type.

4. Choose interviewees with the case organisation by using purposive sampling and secure interview permissions.

5. Pre-test the interview questions with colleagues and iterate each one of them.

6. Send interview questions to the interviewees beforehand and set interview dates.

7. Conduct all interviews using the chosen questions and record and transcribe each interview.

Table 1 The empirical documents used in this study

\begin{tabular}{ll}
\hline Document & Content \\
\hline A report on an ethnographic study & $\begin{array}{l}\text { This study examined the capabilities and challenges } \\
\text { of co-production in the hybrid. A total of } 100\end{array}$ \\
study subjects participated. The study was based \\
upon interviews and observations, and a private \\
company conducted it. The examined municipality \\
published the report
\end{tabular}

Presentation of the management model, governing structures, and joint goals of the hybrid

The document describes actors involved in the governance and management of the hybrid and their tasks. The jointly agreed-upon goals of the organisations forming the hybrid are also presented. This document is an internal document of the municipality

The annual budget of the municipality

This document reveals what the hybrid reported to the external stakeholders in official municipal documents. It reported the number of customers and costs per customer

The quarterly report of the municipality

This document reveals what the hybrid reported to the external stakeholders in official municipal documents. It reported the number of customers and costs per customer

A report describing the hybrid as an innovation platform

This 50-page report provided by the municipality describes the hybrid and its functions and problems in detail 
8. Analyse $50 \%$ of the interview transcripts with theoretical categories using the computer program Atlas.ti.

9. Develop theoretical categories based on the conducted content analysis.

10. Using Atlas.ti, conduct a new content analysis of all interview transcripts and documents with the developed theoretical categories.

11. Report the results.

\subsection{Analytical framework: known challenges of performance dialogues}

We adopted an analytical framework, presented in Table 2, for the content analysis. This framework comprises seven challenge categories, listed in Column 1. The categories are based on key concepts, described in Column 2. In Column 3, these categories' precise content in our research setting is explained further with example statements excerpted from the interviews. This framework was presented originally by Rajala et al. (2018), and it initially was developed from reasons for non-use of performance information. Extant literature used mental models (McGrath 1999), power (Bass and Riggio 2006; Verhoest et al. 2004), information (Bouckaert 1993; Poister 2003), information systems (Abdel-Maksoud et al. 2015), organisational culture (Moynihan 2005) and organisational structure (Goh 2002) to explain non-use of performance information. Because boundary-crossing performance dialogues are based on performance information use, this theoretical framework seems relevant.

\subsection{Challenges of performance dialogues in hybrid organisations}

As we went through 50 percent of the interview transcripts after all the interviews were conducted, we noticed that the analytical framework was too general. To describe the challenges of boundary-crossing performance dialogues within the hybrid organisation, we further developed the framework by using our empirical data. In our case, increasing the intensions (e.g., Blackburn 2016, p. 170, for a definition of intensions) of the concepts enabled us to describe the challenges of boundary-crossing performance dialogues that were evident in interviewees' statements. We increased intensions by creating subcategories under those categories presented by Rajala et al. (2018). Our subcategories had more characteristics than the categories adopted in the previous research. As a result, we were able to report the challenges of boundary-crossing performance dialogues in the chosen hybrid organisation in a more analytical manner. These subcategories are discussed in detail in the following sub-sections.

\subsection{Mental models, motivation and power}

First, we developed two subcategories for the category of mental model. The first identified subcategory was named 'language barriers between member organisations'. This challenge indicated the lack of a common language among representatives of member organisations participating in the boundary-crossing performance dialogues (interviewee 3 ). A representative from a private company expressed this 


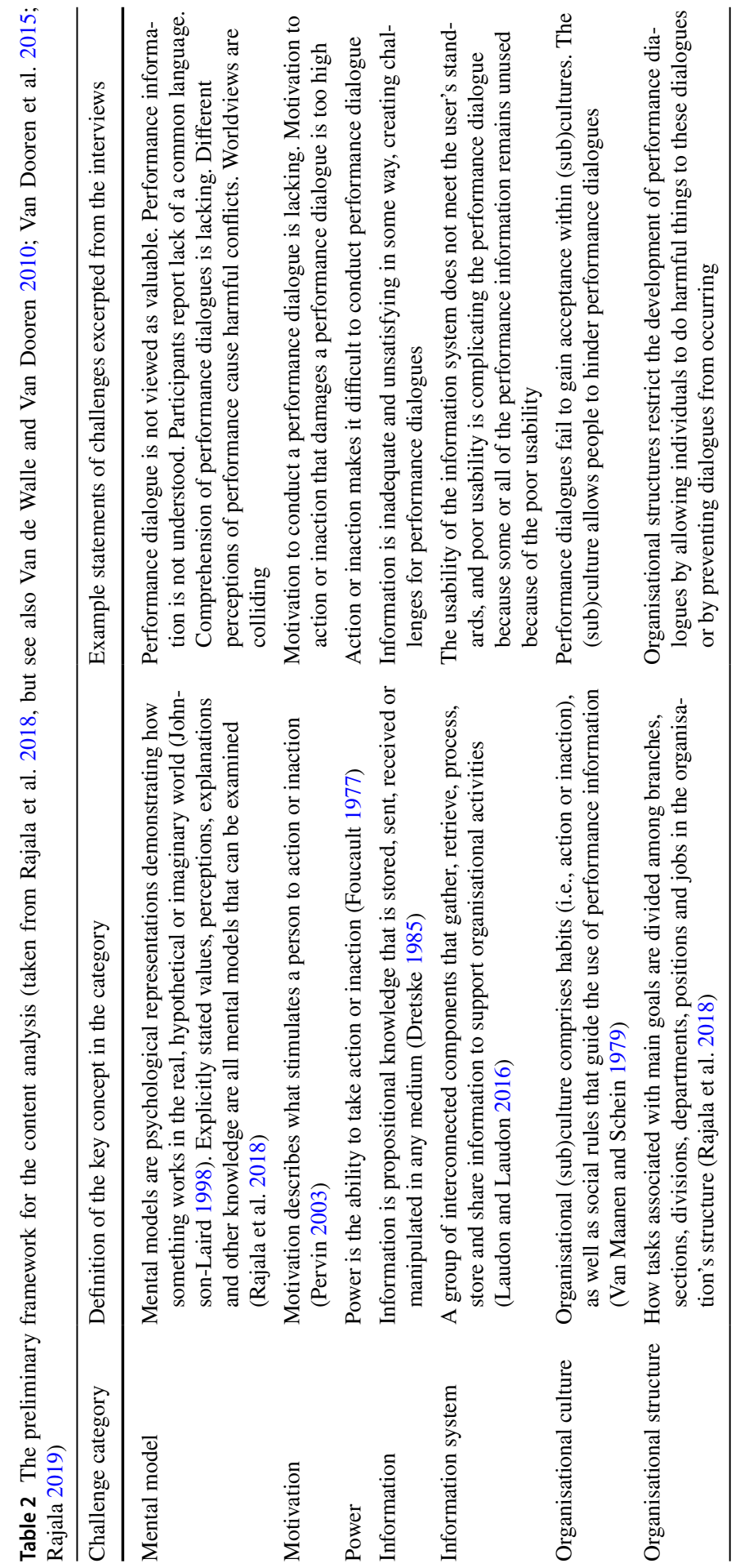


issue in the following manner (document 1): 'We do not speak the same language, as there are so many actors, but this can be resolved'. When asked about the challenges of boundary-crossing performance dialogues, one interviewee stated that one problem is that:

'Our [referring to the representatives from the member organisations] language is not necessarily the same....In my opinion, this [lack of a common language] has been a challenge...generating a common language. This is a key factor...'.

Complications in communication arose as a result. In a hybrid organisation, each member organisation has developed its own performance jargon before joining the hybrid, so it was difficult sometimes to determine a 'common language' in the organs of the hybrid organisation (interviewee 8). This caused complications in information production and information interpretation in the hybrid organisation.

We labelled the second subcategory 'conflicting mindsets of the member organisations'. Here, the participants brought their different organisational values and perceptions to the boundary-crossing performance dialogue, and these collided (interviewee 1). The member organisations' conflicting mindsets led to disagreements about what information should be produced and why (interviewee 11). Statements in the empirical data described the different organisational mindsets in the boundarycrossing performance dialogues this way (interviewee 7 , document 1):

'When we talked about customer service desks [in the hybrid organisation], there were eight different perceptions on what is a customer service desk. Even in such a general matter, there were very different perceptions'.

'One challenge from the perspective of companies is that expectations do not match up. Actors of different size do not understand that start-ups try to sell their services and try to receive payments from testing these services. Cities want that they are paid for operating as platforms [for testing these services offered by start-ups]. These conversations start well, but do not reach a conclusion, as hopes and goals are different'.

We identified two types of motivational challenges: extrinsic (interviewee 9) and intrinsic (interviewee 10). Extrinsically motivated people are driven by external factors, such as rewards and punishments. People who are extrinsically motivated can conduct actions even though the task might not be in and of itself rewarding. This happens because the reward or punishment associated with these actions acts as a motivator (Frey and Osterloh 2001). The extrinsic motivation challenges were caused by the hybrid organisation's inability to sanction sufficient disciplinary actions should a member organisation operate in a way that degraded the performance or performance dialogue. In boundary-crossing performance dialogues, we named challenges relating to extrinsic motivation as 'lack of inter-organisational sanction systems'. Indeed, no incentive systems existed that could be used to force member organisations to do something. As one interviewee stated, 'I do not know 
how we could force to participate those who do not participate even though they are invited [to the meetings]'. Sanctioning also refers to accountability systems that are based on proper monitoring of actions through information systems. However, these monitoring and information systems were lacking in the hybrid organisation, as the following quotations demonstrate (interviewee 2, document 1):

'I do not know exactly what happens to the matters that the steering group has decided. Are they executed or not?... This we do not monitor very much'.

'It depends on the person how the information flows in the service unit, as there is no control for it'.

Compared with extrinsically motivated individuals, intrinsically motivated individuals are driven by interest or enjoyment in the task itself. Thus, intrinsic motivation exists within the individual and does not rely on external pressures, as extrinsic motivation does (Frey and Osterloh 2001). Unfortunately, intrinsic motivation occasionally was lacking in the hybrid organisation because member organisations were not that interested in each other's results, and collaboration was viewed as undesirable or uninspiring. Thus, the subcategory relating to intrinsic motivation was called 'lack of interest in other member organisations'. One interviewee described this challenge as follows (interviewee 9, document 1):

'I'm not interested in what happens in the organisations of [mentions the name of the municipality]. Instead, I'm interested in what happens in [mentions his own organisation by name]'.

'Some employees feel that co-development generates an extra burden that takes time away from their jobs. Some of the employees feel that they have too much to do in their current jobs, so co-development does not raise enthusiasm".

The problem in the hybrid organisation was that it was not easy to create topics that would interest all the member organisations because these organisations had very different tasks. One manager operating in the hybrid described this by stating that 'all the information is not considered as interesting by everyone'. Another interviewee added that 'if there is a meeting...not producing added value or its purpose is somehow vague, one can perhaps skip it'.

When we examined the empirical data by using the category of power, we conceived a subcategory titled 'powerlessness of the member organisations'. Powerlessness was considered to be a lack of influence over the other member organisations, each of which had an equal amount of power in boundary-crossing performance dialogues. Powerlessness in dialogues points to a situation in which a person or multiple people feel powerless when they attempt to break detrimental deadlocks that inhibit improvements in current performance dialogue practices or their outcomes. For example, the companies thought that one of the 
main challenges is 'how to get people interested in co-development' (document 1). Interviewees themselves used the word 'powerless' to describe their incapacity to change things in performance dialogues. Of course, the fact that a manager is feeling powerless means that someone else must have the power to make the change that the manager desires. Thus, we do not mean that a total absence of power exists when we talk about powerlessness. Rather, powerlessness describes the manager's feelings. In the hybrid organisation, all the representatives in the boundary-crossing performance dialogues could have felt powerless when deadlock situations between the representatives occurred. The following quote captures this phenomenon in the hybrid organisation (interviewee 11): 'Although I am a manager in here, I do not have any power to make [certain] decisions [relating to performance dialogues]'. Another statement from the same interview added:

'Efficiency is required from all of us as a whole [talking about the goals of the hybrid organisation]....It is an interesting goal [for the hybrid organisation] because I cannot decide on their budgets [refers to the budgets of the other member organisations]. The budget I can decide is so small even in percentages that trimming it won't do anything'.

\subsection{Information systems and information}

One subcategory was identified under the category of information systems. We conceptualised this category as 'member organisations as information system silos'. When information system silos occurred, the participants had different access rights to information systems in different organisations. Each of the member organisations formed its own information system silo in the hybrid organisation. Indeed, the member organisations already had developed their own information systems to serve their organisational goals. The information systems had been developed before any of the organisations became part of the hybrid organisation, and they were mutually distinct (interviewee 11). These separately conducted development processes meant that integration of these information systems was such a complex process that the hybrid organisation decided to abandon the idea altogether, even though integration could offer better information about the costs and effects of the hybrid organisation (interviewee 6). Two people expressed the existence of these information system silos as follows:

'We do not get the financial figures from our member organisations [operating within the hybrid organisation]. The representatives have been ordered not to give their numbers' (interviewee 11).

'the biggest challenges are, in my opinion, in the information flows if information does not transfer quickly enough... but these can be solved as soon as [information] systems become more easily approachable' (document 1). 
Because the member organisations formed information system silos, multiple information asymmetries existed between participants in the hybrid organisation's boundary-crossing performance dialogues (interviewee 3 ). This affected the performance dialogue in many ways: Time was taken away from the actual use of performance information and expended instead on levelling the pre-existing information asymmetries (interviewee 6).

The subcategory under the concept of information was named 'inability to aggregate the member organisation data'. This subcategory pointed to a lack of aggregated data on member organisations, according to the information user. Producing aggregated information about inputs, processes, workload, outputs, efficiency and outcomes of the organisation network was difficult at the level of the hybrid organisation. The hybrid organisation's main issue was the current data collection procedures. According to one public manager, 'the units collect it differently [she had talked about output information collection in the member organisations]', and 'we have tried to achieve comparability, but we did not achieve this' (interviewee 6).

\subsection{Organisational culture and structure}

Two subcategories under the main category of organisational culture were found: 'clash of organisational cultures' and 'prevailing culture among the member organisations'. The challenge in the hybrid organisation was that it had to deal with member organisations' clashing organisational cultures. Of course, each member organisation had its own internal cultural clashes, but they also had cultural clashes with the other member organisations when boundary-crossing performance dialogues were implemented. The following quotation captures the clash of organisational cultures arising from the attempt to implement boundary-crossing performance dialogues: 'There are participants from different work cultures, and I do understand that some people do not get it that their presence in the meetings could be useful to others' (interviewee 2). Below are other quotations from the hybrid organisation that summarise this challenge (interviewee 7 , document 1 ):

'The most central [challenge] is that we cannot harmonise master data [in the hybrid]....Information is incompatible, and so is the information production....Different [service] units [within the hybrid]...have different cultural frameworks that create mindsets guiding the information production....Common understanding in information utilisation cannot be reached because the mindsets are different'.

'The public sector is very cautious, and failures are not tolerated....This is a big challenge when one is talking about the culture of experimentation. The culture of the city can be a challenge, and it needs to be developed so that codevelopment can function'.

The prevailing culture permitted behaviour that was detrimental to performance dialogues and allowed it to become a part of the organisational culture. As a sign of detrimental behaviour permitted by the prevailing culture, one interviewee stated that 
'the weakness of the steering group...is a low attendance rate in meetings, as there are three people in them at best'. As nine service units exist in the hybrid, many representatives of different organisations did not attend. More challenges relating to the prevailing culture were viewed in the documents, and one document contained the following statement: 'Some employees are persistently staying in their own teams, and they do not try to get to know others, even if one asks nicely'.

Because member organisations were equal in terms of power, the hybrid organisation had to accept the fact that dissent among member organisations on some issues could prevent certain types of performance dialogues. Indeed, the lack of sanction systems meant that detrimental behaviour toward the performance dialogues had to be tolerated. One manager described this situation by stating, 'I do not know how we can force those to participate who do not participate [in boundary-crossing performance dialogues] now' (interviewee 8).

We found three subcategories of challenges associated with organisational structures. First, we observed 'inter-organisational territorialism'. Territorialism here is understood as human behaviour characterised by the defence of a particular area, sphere of activity or influence. In short, territorialism is possessiveness. People defended their organisations (territories) by blocking new information systems or tasks suggested to them by someone else operating in the hybrid organisation. In a hybrid organisation, examples of inter-organisational territorialism were found that blocked collaboration, and this inter-organisational territorialism was even understood and accepted by other representatives of member organisations. An interviewee described this by stating that 'I can understand why [mentions the name of one service unit] does not understand how they could collaborate with [the] child health clinic or library'. Another sign of inter-organisational territorialism was one statement from the documents (document 1):

'Many state that health services are detached from other services in the service market (i.e., the hybrid organisation). The common aim is that this segregation would not prevent collaboration in the future'.

Within the hybrid organisation, each member organisation had its own territory outlined by organisational boundaries. The member organisations' representatives also had the option to exercise territorialism because the representatives had an equal amount of power in dialogues. The member organisations even encouraged their agents to be territorial whenever their interests were in jeopardy (interviewee 11). This can be viewed from earlier quotations demonstrating how joint performance information systems could not be implemented because member organisations either did not provide their information or did not want to expend the effort to change their current information systems. Based on the interviews, a hybrid organisation brings inter-organisational territorialism into the organisation (interviewee 1) and makes it an internal matter, rather than an external one.

Second, we labelled a subcategory 'representative line-up rotation in boundary-crossing performance dialogues', which refers to a cycle in which representatives of the member organisation change constantly in the dialogues or do not 
show up, which, in turn, creates difficulties for the performance dialogue. In the hybrid organisation, one interviewee stated:

'The representatives [of some member organisations] have changed every time....In fact, I do not even know what is the correct line-up in the steering group'.

'The staff is changing at a high rate. It is burdensome'.

Rotation was named as a challenge in the hybrid organisation. The hybrid organisation could not force anyone from the member organisations to attend the meetings (interviewee 1). According to an interviewee, 'the line-up has constantly changed' in the steering group (interviewee 2). This was viewed as problematic because important voices were being left out of the performance dialogues, and the constant rotation hampered continuity.

Third, we identified a phenomenon that we conceptualised as 'incompatible tasks of the member organisations'. In this subcategory, performance dialogues in the hybrid organisation were incompatible with member organisation(s)' tasks. Therefore, the connection between the topic addressed in the performance dialogue and the representative(s)' tasks was weak, or sometimes even non-existent. Due to these incompatible tasks, representatives sometimes viewed performance dialogues as a waste of time. Consider this statement from interviewee 9:

'I do not participate in every steering group meeting. I look at the meeting agenda. There are meetings that relate very little to [mentioned his organisation's name] and to these, I do not necessarily participate....I feel that I do not have anything to give or receive from these meetings'.

The organisations' incompatible tasks mainly resulted from the municipality's dominant role in the hybrid organisation and because all matters relevant to the municipality were not relevant to the other member organisations. Many municipal units were involved in the hybrid organisation; therefore, municipal issues were addressed more often in the dialogues. As one manager put it, 'there is the world of [mentioned the name of his organisation], and there is the world of the city, and the city is not so interested in our figures' (interviewee 9). One of the documents (document 1) revealed that 'time pressures associated with service unit tasks made it more difficult for the service units to participate [in] the activities of the hybrid organisation'.

\subsection{Summarising empirical findings}

The saturation of findings was achieved in this study (see Table 3), as empirical data demonstrates that boundary-crossing performance dialogues between public and private sector actors are confronted with the challenges reported in this study. Different performance management practices between public, private and third sector organisations partly explain why it was difficult to create common performance management systems for the hybrid organisation. For example, differences existed in 
Table 3 Saturation of findings

Challenge of boundary-crossing performance dialogue
How many interviewees mentioned this challenge?
How many documents mentioned this challenge?

\begin{tabular}{|c|c|c|}
\hline Language barriers between member organisations & 8 & 2 \\
\hline Conflicting mindsets of the member organisations & 10 & 2 \\
\hline Lack of inter-organisational sanction systems & 6 & 2 \\
\hline Lack of interest in other member organisations & 8 & 2 \\
\hline Powerlessness of the member organisations & 8 & 2 \\
\hline Member organisations as information system silos & 9 & 2 \\
\hline Inability to aggregate the member organisation data & 10 & 2 \\
\hline Clash of organisational cultures & 11 & 2 \\
\hline Prevailing culture among the member organisations & 9 & 2 \\
\hline Inter-organisational territorialism & 9 & 2 \\
\hline $\begin{array}{l}\text { Representative line-up rotation in boundary-cross- } \\
\text { ing performance dialogues }\end{array}$ & 8 & 2 \\
\hline Incompatible tasks of the member organisations & 9 & 2 \\
\hline
\end{tabular}

the organisations' mental models concerning performance. Public, private and third sector organisations also were dissimilar in terms of the information that they collected, and they even applied different methods to collect the same kind of information. Moreover, the information systems in these organisations deviated remarkably from each other. Finally, the organisational cultures and structures supporting their performance were quite different because each organisation served different purposes, and the professions included in these organisations also differed. The hybrid organisation itself did not have any formal power over the member organisations, and proper motivation schemes were not adopted in the hybrid setting. Thus, reconciling differences and finding a common ground for mutual performance management were based on member organisations' willingness. When this willingness was not forthcoming, deadlocks occurred, and the lack of formal power and motivation schemes in the hybrid organisation was viewed as a challenge.

\section{Conclusions}

Hybrid organisations contain many organisational disparities that can cause conflicts in performance management. This makes performance dialogues especially relevant to these types of organisations because such dialogues often are used to transform conflicts into cooperation. Considering the hybrid organisation's characteristics requires active inter-organisational dialogue when performance management systems are being designed and used. For example, using the performance dialogues to understand goal incongruence between the organisations comprising the hybrid organisation can be very beneficial to the success of 
performance management. However, creating a functional performance dialogue also can be challenging in many ways.

In this study, we sought to identify the challenges of boundary-crossing performance dialogue in a hybrid organisation. This issue is relevant not merely due to performance dialogues' important role in all organisations (e.g., Agostino and Arnaboldi 2015, 2018), but also particularly because of our limited understanding of performance dialogues' impacts on different forms of hybrid organisations. Accordingly, this paper has explored the problems of boundary-crossing performance dialogues in the context of particular hybrid organisation. As a result, we found many challenges and described them in a detailed way in our analysis. With this analysis, the study revealed relationships between inter-organisational factors and obstacles with boundary-crossing performance dialogues. Conflicting mindsets between member organisations, member organisations as information system silos, inter-organisational territorialism, and clashes of organisational cultures are all examples of inter-organisational factors that can cause issues in performance dialogues. Some of the problems which can arise include inhibition of innovation, and limitations placed on the learning and knowledge-sharing potential which is normally embedded in boundary-crossing performance dialogues. In general, the inter-organisational factors described in this study were harmful due to the fact that they were detrimental to an environment open to respectful communication of views on performance. As respectful and open communication is a bedrock of every effective dialogue (Rajala et al. 2018), issues emerge when these practices are lacking. Thus, the relationships identified by this study create new insights into the systems and practices of hybrid performance management.

It seems intuitive to claim that the challenges of boundary-crossing performance dialogues in hybrid organisations have something to do with the hybrids' general characteristics (e.g., Johanson and Vakkuri 2017). Because this study did not focus on describing how the hybrid organisation's characteristics can create the challenges that we identified, a need exists to examine this in future research. As an example, future studies could address how different forms of social and economic control create, e.g., clashes between organisational cultures, or how different funding methods shape the hybrid organisation's performance management system. Furthermore, it can be concluded that additional theoretical work addressing the conceptual relationships between the challenges of boundarycrossing performance dialogues and the general characteristics of hybrids is needed.

Because the empirical examinations showed what caused the challenges of boundary-crossing performance dialogues, they also presented a model describing how these challenges occurred. However, further testing is needed before this model can be accepted as a general theory on boundary-crossing performance dialogues. As a methodological contribution, we created a conceptual framework that can be used to study the challenges of boundary-crossing performance dialogues occurring between public and private sector actors in hybrid organisations. In this research, we tested two conceptual frameworks in the analysis section, which revealed that more analytical frameworks would be useful in understanding the characteristics of the challenges associated with boundary-crossing performance dialogues. This 
conceptual framework also proposes new concepts for the performance dialogue theories (e.g., Moynihan 2005; Rajala et al. 2018; Rajala and Laihonen 2019).

The results of this study have several managerial implications. First, because boundary-crossing performance dialogues are platforms that reflect the state of the organisation, they suffer from the same general issues which challenge the hybrid form of organising. These problems are related to motivational challenges and incompatible information systems, as well as the lack of common mindsets and language between people working in different areas of the hybrid organisation. Inadequate organisation culture and structures are also an issue. Second, as the complications of forming hybrids engender costs, practitioners should consider carefully whether the benefits of establishing such an organisation outweigh the costs arising from it. Here, the central question is whether it makes more sense for these organisations to work independently or as a hybrid. Finally, practitioners should also keep in mind that boundary-crossing performance dialogues are only one coordination instrument amongst others which can be utilised to shape hybrids. However, boundary-crossing performance dialogues can also be a vital coordination tool when regularly used to solve difficult and complicated disagreements.

In this study, we used a case study approach, and for this reason, the results cannot be generalised (e.g., Abdel-Kader et al. 2009). Other limitations of the study include the limited number of interviewees and the fact that we did not interview representatives from the private sector. The views of the private sector actor were examined from secondary data (i.e., documents produced by the hybrid organisation) as these contained direct quotations from company representatives. When one is conducting qualitative content analysis, the observer-expectancy effect always runs the risk of biasing results. To tackle doubts concerning observer-expectancy effect, we have provided quotations from the challenges of boundary-crossing performance dialogues. From these quotations, the reader should be able to discern whether we described the challenge arising from the interviews correctly. The analytical framework created in this study was built from the descriptions we used to depict the challenges of boundary-crossing performance dialogues that interviewees described to us. Because saturation of interview findings (see Table 3) confirmed our results about the challenges of boundary-crossing performance dialogues, and the analysed documents provided additional support for the interview findings, we are confident that specific challenges of boundary-crossing performance dialogues existed in the examined hybrid organisation. However, we do acknowledge that the way that we chose to describe the challenges seen in the interview is our construction that attempts to convey interviewees' views. As the created analytical framework is our construction, it means that constructivism describes our research approach.

Despite these limitations, we think that our research has provided fertile ground for future research to address and more fully test our theoretical ideas about the challenges of performance dialogues in hybrid settings. Thus, we call for more research on the ideas proposed here so that more knowledge on dialogues as performance management practices in hybrid and public organisations can be gathered. This new knowledge is valuable in attempts to move to the type of inter-organisational performance governance described by Bouckaert and Halligan (2008). 
Open Access This article is distributed under the terms of the Creative Commons Attribution 4.0 International License (http://creativecommons.org/licenses/by/4.0/), which permits unrestricted use, distribution, and reproduction in any medium, provided you give appropriate credit to the original author(s) and the source, provide a link to the Creative Commons license, and indicate if changes were made.

\section{Appendix 1: Interview questions}

Thematic interview questions categorised according to the theoretical framework.

\section{General view on performance dialogues}

1. How would you describe the dialogues about performance?

\section{Performance information and performance information system}

2. Are there problems related to performance information and the systems providing it?

\section{Organisational structure and motivation}

3. Who participates when organisational goals and performance indicators are determined, and actions are being decided based on the performance information?

4. Are all necessary participants present? Why/Why not?

\section{Mental models}

5. Is the performance information provided useful to you?

6. Are there different interpretations/views about the performance information available?

\section{Power and organisational culture}

7. Do people listen and respect different interpretations/views about the performance information?

8. How do you resolve conflicting views and develop conversational culture in the organisation?

\section{References}

Abdel-Kader, M. G., Lin, E. Y.-C., \& Connect, Palgrave. (2009). Performance measurement of new product development teams: A case of the high-tech sector. Basingstoke: Palgrave Macmillan. 
Abdel-Maksoud, A., Elbanna, S., Mahama, H., \& Pollanen, R. (2015). The use of performance information in strategic decision making in public organisations. International Journal of Public Sector Management, 28(7), 528-549.

Agostino, D., \& Arnaboldi, M. (2015). The New public management in hybrid settings: New challenges for performance measures. International Review of Public Administration, 20(4), 353-369.

Agostino, D., \& Arnaboldi, M. (2018). Performance Measurement Systems in Public Service Networks. The What, Who and How of Control. Financial Accountability \& Management p 1-14.

Agranoff, R., \& McGuire, M. (2001). American federalism and the search for models of management. Public Administration Review, 61(6), 671-681.

Aguinis, H. (2009). Performance management. Upper Saddle River: Pearson Prentice Hall.

Bass, B. M., \& Riggio, R. E. (2006). Transformational leadership. Mahwah, NJ: Erlbaum.

Blackburn, S. (2016). The Oxford dictionary of philosophy. Oxford: Oxford University Press.

Bouckaert, G. (1993). Measurement and meaningful management. Public Productivity \& Management Review, 17, 31-43.

Bouckaert, G., \& Halligan, J. (2008). Managing performance. international comparisons. Oxon, UK: Routledge.

Christensen, T., \& Laegreid, P. (2011). Complexity and hybrid public administration-theoretical and empirical challenges. Public Organisations Review, 11(4), 407-423.

Cyert, R. M., \& March, J. G. (1963). A behavioural theory of the firm. Englewood Cliffs: Prentice Hall.

Dretske, Fred. (1985). Precis of knowledge and the flow of information. In Hilary Kornblith (Ed.), Naturalizing epistemology (pp. 169-187). Cambridge, MA: MIT Press.

Eprahim, A., Batilana, J., \& Mair, J. (2014). The governance of social enterprises: Mission drift and accountability challenges in hybrid organisations. Research in Organisational Behavior, 34, 81-100.

Foucault, M. (1977). Power/Knowledge, edited by Colin Gordon. New York: Pantheon Books.

Frey, B. S., \& Osterloh, M. (Eds.). (2001). Successful management by motivation: Balancing intrinsic and extrinsic incentives. Springer Science \& Business Media.

Goh, S. C. (2002). Managing effective knowledge transfer: An integrative framework and some practice implications. Journal of Knowledge Management, 6(1), 23-30.

Halligan, J., Sarrico, C. S., \& Lee Rhodes, M. (2012). On the road to performance governance in the public domain? International Journal of Productivity and Performance Management, 61(3), 224-234.

Hansmann, H. (1996). The ownership of enterprise. Cambridge, MA: The Belknap Press of Harvard University Press.

Hatry, P. (2006). Performance measurement: Getting results. Washington DC: The Urban Institute.

Hodge, C., \& Greve, C. (2007). Public private partnerships: An international performance review. Public Administration Review, 67(3), 545-558.

Hodges, R. (2012). Joined-up government and the challenges to accounting and accountability researchers. Financial Accountability \& Management, 28(1), 26-51.

Johanson, J., \& Vakkuri, J. 2017. Governing Hybrid Organisations. Exploring Diversity of Institutional Life. Routledge. ISBN 9781138655829.

Johnson-Laird, P. (1998). Imagery, visualization, and thinking. In J. Hochberg (Ed.), Perception and cognition at century's end (pp. 441-467). New York: Academic Press.

Jordana, J., \& Levi-Faur, D. (2004). The politics of regulation: Institutions and regulatory reforms for the age of governance. Cheltenham, UK: E. Elgar.

Kamminga, P. E., \& Van der Meer-Kooistra, J. (2007). Management control patterns in joint venture relationships: A model and an exploratory study. Accounting, Organizations and Society, 32(1-2), $131-154$.

Kelly, J. M. (2005). The Dilemma of the unsatisfied customer in a market model of public administration. Public Administration Review, 65(1), 76-84.

Kenno. (2017). Etnographic research on service market. Helsinki: Kenno Oy.

Kreps, T. A., \& Benoît, M. (2011). 'Doing Well by Doing Good'’? Ambivalent moral framing in organisations. Research in Organisational Behavior, 31, 99-123.

Laihonen, H., \& Mäntylä, S. (2017). Principles of performance dialogue in public administration. International Journal of Public Sector Management, 30(5), 414-428.

Laudon, K. C., \& Laudon, J. P. (2016). Management information system. Pearson Education India.

Lee, C., \& Nowell, B. (2015). A framework for assessing the performance of nonprofit organizations. American Journal of Evaluation, 36(3), 299-319.

Liu, J., Love, P., Smith, J., Regan, M., \& Sutrisna, M. (2014). Public-private partnerships: a review of theory and practice of performance measurement. International Journal of Productivity and Performance Management, 63(4), 499-512. 
Mayring, P. (2000). Qualitative Inhaltsanalyse. Grundlagen und Techniken (7th ed.). Weinheim: Deutscher Studien Verlag.

McDavid, J. C., \& Hawthorn, L. R. L. (2006). Program evaluation \& performance measurement: An introduction to practice. Thousand Oaks: SAGE Publications.

McGrath, R. G. (1999). Falling forward: real options reasoning and entrepreneurial failure. Academy of Management Review, 24(1), 13-30.

McGuire, M. (2002). Collaborative public management: Assessing what we know and how we know it. Public Administration Review, 66(s1), 33-43.

Ménard, C. (2004). The economics of hybrid organisations. Journal of Institutional and Theoretical Economics, 160, 345-376.

Meuser, M., \& Nagel, U. (2009). The expert interview and changes in knowledge production. In A. Bogner, B. Littig, \& W. Men (Eds.), Interviewing experts (pp. 17-42). London: Palgrave Macmillan.

Micheli, P., \& Kennerley, M. (2005). Performance measurement frameworks in public and non-profit sectors. Production Planning \& Control, 16(2), 125-134.

Moynihan, D. (2005). Goal-based learning and the future of performance management. Public Administration Review, 65(2), 203-216.

Pache, A.-C., \& Santos, F. (2013). Inside the Hybrid Organisation: Selective coupling as a response to competing institutional logics. Academy of Management Review, 56(4), 972-1001.

Patton, M. (2002). Qualitative research \& evaluation methods. California: Sage.

Pervin, L. (2003). The science of personality (2nd ed.). New York: Oxford University Press.

Philoppopoulos-Mihalopoulos, A. (2012). Suspension of suspension: Notes on the hybrid. In N. Åkerstrøm Andersen \& I.-J. Sand (Eds.), Hybrid forms of governance: Self-suspension of power (pp. 12-29). Chippenham: Palgrave Macmillan Publisher.

Poister, T. H. (2003). Measuring performance in public and nonprofit organizations. San Francisco, CA: Wiley.

Pollitt, C., \& Bouckaert, G. (2004). Public management reform: A comparative analysis. Oxford: Oxford University Press.

Power, M. (1997). The audit society. Rituals of Verification. Oxford: Oxford University Press.

Provan, K. G., \& Milward, H. B. (2001). Do networks really work? A framework for evaluating publicsector organizational networks. Public administration review, 61(4), 414-423.

Rajala, T. (2019). Mind the information expectation gap. Journal of the Knowledge Economy, 10(1), $104-125$.

Rajala, T., \& Laihonen, H. (2019). Managerial choices in orchestrating dialogic performance management. Baltic Journal of Management, 14(1), 141-157.

Rajala, T., Laihonen, H., \& Haapala, P. (2018). Why is dialogue on performance challenging in the public sector? Measuring Business Excellence, 22(2), 117-129.

Reay, T., \& Hinings, C. R. (2009). Managing the rivalry of competing institutional logics. Organisation Studies, 30(6), 629-652.

Schläfke, M., Silvi, R., \& Möller, K. (2012). A framework for business analytics in performance management. International Journal of Productivity and Performance Management, 62(1), 110-122.

Simons, H. (2009). Case study research in practice. London: SAGE.

Thomas, G. (2011). A typology for the case study in social science following a review of definition, discourse, and structure. Qualitative Inquiry, 17(6), 511-521.

Thomas, A., Barton, R., \& Chuke-Okafor, C. (2008). Applying lean six sigma in a small engineering company-a model for change. Journal of Manufacturing Technology Management, 20(1), $113-129$.

Thynne, I. (2011). Ownership as an instrument of policy and understanding in the public sphere: Trends and research Agenda. Policy Studies, 32(3), 183-197.

Van de Walle, S., \& Van Dooren, W. (2010). How is information used to improve performance in the public sector? Exploring the dynamics of performance information. In K. Walshe, G. Harvey, \& P. Jas (Eds.), Connecting knowledge and performance in public services (pp. 33-54). Cambridge: Cambridge University Press.

Van Dooren, W., Bouckaert, G., \& Halligan, J. (2015). Performance management in the public sector. Routledge: Taylor \& Francis Group.

van Helden, J., \& Reichard, C. (2016). Commonalities and differences in public and private sector performance management practices; a literature review. In M. J. Epstein, F. Verbeeten, \& S. K. Widener (Eds.), Performance measurement and management control: contemporary issues (Vol. 31, pp. 309-352). Emerald: Egmore. 
Van Maanen, J., \& Schein, E. (1979). Towards a Theory of Organizational Socialization. Cambridge: MIT Press.

Verhoest, K., Peters, B. G., Bouckaert, G., \& Verschuere, B. (2004). The study of organizational autonomy: a conceptual review. Public Administration and Development, 24, 101-118.

Vo, A. T., Christie, C. A., \& Rohanna, K. (2016). Understanding evaluation practice within the context of social investment. Evaluation, 22(4), 470-488.

Yin, R. K. (2009). Case study research—design and methods (4th ed.). Thousand Oaks, CA: Sage.

Publisher's Note Springer Nature remains neutral with regard to jurisdictional claims in published maps and institutional affiliations.

Tomi Rajala MA, has graduated at the University of Tampere. He has specialized in local public economics. Currently Rajala works as a project researcher in the hybrid organization project and as a lecturer in public financial management at the Faculty of Management and Business. As a PhD student, he is researching performance public sector outcome measurement. Along with these tasks, Rajala is part of a research project focusing on performance dialogues. Previously he has worked in municipalities and Statistics Finland with government productivity statistics.

Harri Laihonen is a research director at Faculty of Management and Business, Tampere University, Tampere, Finland. Harri's research interests lie in the fields of knowledge management and performance management. Within these fields, his current research projects investigate how performance information can be more efficiently used to support decision-making and organizational learning through performance dialogue. At moments, Harri is operating mostly in the public sector but the phenomena are general. Service systems and hybrid organizations provide extremely interesting contexts for the research in different sectors.

Jarmo Vakkuri is Professor at the Faculty of Management and Business, Tampere University, and the director of the research group on Public Financial Management. His research concentrates for instance on performance measurement in public administration, theories of decision-making, hybrid organizations and governance, and urban policy-making. Vakkuri is the director of the HYPER project (Performance measurement for hybrid governance), and one of the directors of the "Beyond MALPE coordination: integrative envisioning" (BEMINE), both funded by the Academy of Finland. 